\title{
INTERSPECIFIC VARIATION OF PHOSPHOGLYCERATE KINASE IN DROSOPHILA
}

\author{
Fred J. Oelshlegel, JR. and George J. Brewer \\ Department of Human Genetics, University of Michigan Medical School, Ann Arbor, MI 48104 U.S.A.
}

(Received 8 July 1974)

\begin{abstract}
The phosphoglycerate kinase electrophoretic banding patterns of several Drosophila species were studied.

2. Three banding types were noted: A type with a slowly migrating band of activity, a type with a faster migrating band of activity, and a type with an intermediate migrating band.

3. These banding types appeared to be species specific and may be useful in evolutionary or taxonomical studies.
\end{abstract}

\section{INTRODUCTION}

THERE has been much recent interest in the enzyme phosphoglycerate kinase [E.C. 1.1.1.95]. Much effort has been devoted to defining its regulatory and functional roles in glycolysis. However, major recent interest has arisen from the observation demonstrating that the gene determining phosphoglycerate kinase is $\mathrm{X}$ linked in mammals (Valentine et al., 1969; Cooper et al., 1971; Meera Khan et al., 1971). Polymorphisms have been demonstrated in phosphoglycerate kinase electrophoretic banding patterns in kangaroos (Cooper et al., 1971; Vandeberg, Cooper, \& Sherman, 1973), and in a human population from New Guinea (Chen et al., 1971). However in most human samplings the enzyme has been rather monomorphic except for rare variants (Beutler, 1969; Chen et al., 1971; Chen \& Giblett, 1972). Ritter \& Schmitt (1974) have recently demonstrated an interspecific variability in this enzyme in the primate order. We have noted a similar interspecific variability within the Drosophila genus and will report on this in this paper.

\section{MATERIALS AND METHODS}

Drosophila sources. Drosophila species were kindly provided by several persons. In most cases the species were laboratory stocks cultured in small bottles and might therefore not show the same variability as the original wild populations. The one exception was a cage population of $D$. melanogaster which was initiated with 26 pregnant females collected in Ann Arbor. This population could fairly accurately represent the Ann Arbor natural population in major phenotypes and genotypes. Samples of $D$. willistoni, D. nebulosa, D. simulans, D. pseudoobscura $C H, D$. pseudoobscura $A R, D$. virilis, $D$. americana, $D$. americana-texana, $D$. novamexicana, and $D$. mercaptorum were provided by $T$. $M$. Riziki of the University of Michigan. S. Sluss and W. R. Heed of the University of Arizona provided the D. nannoptera, D. acanthoptera, and D. cardini. Samples of D. melano- gaster, D. persimilis, D. affinis, D. hydei, D. robusta, D. immigrans, D. pseudoobscura, and $D$. buskii were provided by G. Hooper of Marist College. H. J. Barr of the University of Illinois provided samples of $D$. simulans $y w, D$. virilis, $D$. hydei, D. melanopola, D. fulvimaculoides, and D. tuniditarsus. B. Cort of Washington University provided $D$. virilis, $D$. melanica, D. paramelanica, D. melanissima, D. euronotus, and D. multispina. Finally, D. D. Miller of the University of Nebraska supplied D. affinis, D. algonquin, D. athabasca (eastern), D. athabasca (western), D. azteca, D. narragansett, and D. tolteca.

Electrophoresis and staining. Starch gels were prepared and run for $4 \mathrm{hr}$ using the $\mathrm{pH} 7$ histidine gel and citrate buffer system and electrophoretic set up described by Brewer (1970) for pyruvate kinase. Individual flies were extracted by grinding them with a glass rod in a test tube containing a few drops of the histidine buffer. The resultant extract was then placed in the appropriate gel slot and subjected to electrophoresis. At the end of the run the gel was sliced and stained for phosphoglycerate kinase as described by Oelshlegel \& Brewer (1972). (There is an error in the original publication; for the ATP detection system, the concentration of $\mathrm{MgCl}_{2}$ is $0.011 \mathrm{M}$, of G6PD is $0.5 \mathrm{mg} / 100 \mathrm{ml}$ and $\mathrm{HK}$ is $0 \cdot 1 \mathrm{mg} / 100 \mathrm{ml}$ ).

\section{RESULTS AND DISCUSSION}

Three basic banding patterns were noted in our study. Some Drosophila species had a phosphoglycerate kinase which migrated relatively slowly (about 2 $\mathrm{cm}$ from the origin and called an " $\mathrm{S}$ " band for our purposes), one species (D. multispina) had a phosphoglycerate kinase with a relatively fast migration (about 3.5 $\mathrm{cm}$ from the origin and called an " $\mathrm{F}$ " band), while the remaining species had a phosphoglycerate kinase with a band of intermediate mobility (I). In addition to a major phosphoglycerate kinase band, all three banding types had a minor band slightly ahead and a minor band slightly behind the major band. None of these 
bands stained in the adenylate kinase system (Oelshlegel \& Brewer, 1972).

Table 1 lists the Drosophila species we studied along with the banding types we found. Also listed are the number of individuals studied within each species. There seems to be little relation of gel phenotype type to geographical area of sampling. However, an inspection of the data does indicate that there is a species specificity in phosphoglycerate kinase gel banding pat- terns. Such specificity could be utilized in evolutionary or taxonomical studies. There seems to be a tendency for species within a group to have the same phosphoglycerate kinase phenotype although there are exceptions. Because of the laboratory stock nature and small numbers of the species we studied, no statements can be made about the degree of polymorphisms within a species. As mentioned, a phosphoglycerate kinase polymorphism has been found in a natural population

Table 1. Phosphoglycerate kinase electrophoretic banding patterns of several species of Drosophila

\begin{tabular}{|c|c|c|c|c|}
\hline Species & & $\begin{array}{c}\text { Original } \\
\text { collection site* }\end{array}$ & $\begin{array}{l}\text { Band } \\
\text { type }\end{array}$ & $\begin{array}{c}\text { No. } \\
\text { analyzed }\end{array}$ \\
\hline \multicolumn{5}{|l|}{ Sophophora Subgenera } \\
\hline \multirow[t]{2}{*}{ willistoni group } & D. willistoni & Icana, Brazil & I & 9 \\
\hline & D. nebulosa & Belem, Brazil & I & 16 \\
\hline nannoptera group & D. nannoptera & Oxaca, Mexico & I & 3 \\
\hline \multirow[t]{4}{*}{ melanogaster group } & D. melanogaster & Ann Arbor, Michigan & I & 225 \\
\hline & D. melanogaster & Hyde Park, New York & I & 2 \\
\hline & D. simulans & Missouri & I & 17 \\
\hline & D. simulans $y w$ & - & I & 28 \\
\hline \multirow[t]{12}{*}{ obscura group } & D. pseudoobscura $\mathrm{CH}$ & - & $S$ & 9 \\
\hline & D. pseudoobscura $A R$ & - & $\mathbf{S}$ & 9 \\
\hline & D. pseudoobscura & Pine, Arizona & $\mathrm{S}$ & 1 \\
\hline & D. persimilis & Yosemite, California & $S$ & 5 \\
\hline & D. affinis & Grand Rapids, Minnesota & I & 9 \\
\hline & D. affinis & Hyde Park, New York & I & 6 \\
\hline & D. algonquin & Halstad, Minnesota & $\mathrm{S}$ & 3 \\
\hline & D. athabasca (east) & L. Shaintheau, Minnesota & $\mathrm{s}$ & 1 \\
\hline & D. athabasca (west) & Eugene, Oregon & $\mathbf{S}$ & 1 \\
\hline & D. azteca & Chilpancihgo, Mexico & I & 1 \\
\hline & D. narragansett & Bastrop Pk. Texas & $S$ & 1 \\
\hline & D. tolteca & Medellin, Colombia & $\mathrm{S}$ & 1 \\
\hline \multicolumn{5}{|l|}{ Sordophila Subgenera } \\
\hline & D. acanthoptera & Oxaca, Mexico & I & 4 \\
\hline \multicolumn{5}{|l|}{ Drosophila Subgenera } \\
\hline \multirow[t]{6}{*}{ virilis group } & D. virilis & Dexalucan, Texas & $\mathbf{S}$ & 36 \\
\hline & D. virilis & - & $\mathrm{S}$ & 4 \\
\hline & D. virilis & Texmelican, Texas & $\mathrm{S}$ & 1 \\
\hline & D. americana & Anderson, Texas & $\tilde{S}$ & 9 \\
\hline & D. americana-texana & New Orleans, Texas & $\mathbf{S}$ & 46 \\
\hline & D. novamexicana & Texas & $\mathrm{S}$ & 10 \\
\hline \multirow[t]{5}{*}{ repleta group } & D. mercaptorum & - & $\mathrm{S}$ & 24 \\
\hline & D. hydei & - & $\mathbf{S}$ & 7 \\
\hline & D. hydei & Hyde Park, New York & $\mathrm{S}$ & 3 \\
\hline & D. melanopola & - & I & 4 \\
\hline & D. fulvimaculoides & 一 & I & 3 \\
\hline robusta group & D. robusta & Princeton, New Jersey & I & 14 \\
\hline immigrans group & D. immigrans & Hyde Park, New York & I & 3 \\
\hline \multirow[t]{4}{*}{ melanica group } & D. melanica & St. Louis, Missouri & I & 7 \\
\hline & D. paramelanica & St. Louis, Missouri & I & 1 \\
\hline & D. melanissima & Columbia, South Carolina & I & 2 \\
\hline & D. euronotus & St. Louis, Missouri & $\mathbf{I}$ & 1 \\
\hline cardini group & D. cardini & Duaca, Venezuela & I & 3 \\
\hline funebris group & D. multispina & Sapporo Forest, Japan & $\mathrm{F}$ & 13 \\
\hline \multicolumn{5}{|l|}{ Drosophila Subgenera } \\
\hline & D. buskii & Princeton, New Jersey & I & 5 \\
\hline \multirow{2}{*}{ Other } & & & & \\
\hline & D. tuniditarsus & - & I & 3 \\
\hline
\end{tabular}

* In some cases original collection site not known or only incompletely known and is listed accordingly. 
of D. melanogaster (Chew \& Cooper, 1973). Three phosphoglycerate kinase alleles were found based on gel mobility; $\mathrm{Pgk}^{3}$ with a gene frequency of 0.97 , $\mathrm{Pgk}^{2}$ of 0.01 , and $\mathrm{Pgk}^{1}$ of 0.01 . $\mathrm{A} \mathrm{Pgk}^{2}-\mathrm{Pgk}^{3}$ polymorphism also was found in a laboratory stock of $P$. hydei. No polymorphisms were found in a natural population of $D$. simulans and one of $D$. immigrans. From the Ann Arbor D. melanogaster population we studied it can be concluded that if a polymorphism exists in this population the minor alleles are not common. Our gel band types can not be compared to those of Chew \& Cooper since electrophoretic conditions differ in the two studies.

Acknowledgements-The authors wish to thank $\mathrm{T}$. Leonard for providing technical assistance and the previously mentioned individuals for providing the Drosophila species.

\section{REFERENCES}

BEUTLER E. (1969) Electrophoresis of phosphoglycerate kinase. Biochem. Genet. 3, $189-195$.

BREWER G. J. (1970) An Introduction to Isozyme Techniques, pp. 106-108. Academic Press, New York.

Chen S. H. \& Giblett E. R. (1972) Phosphoglycerate kinase: additional variants and their geographic distribution. Am. J. Hum. Genet. 24. 229-230.
Chen S., Malcolm L. A., Yoshida A. \& Giblett E. R. (1971) Phosphoglycerate kinase: an X-linked polymorphism in man. Am. J. Hum. Genet. 23, 87-91.

CHEW G. K. \& COOPER D. W. (1973). Phosphoglycerate kinase polymorphism in Drosophila. Biochem. Genet. 8 , 267-270.

Cooper D. W., Vandeberg J. L., Sharman G. B. \& Poole W. E. (1971) Phosphoglycerate kinase polymorphism in kangaroos provides further evidence for maternal $\mathrm{X}$ inactivation. Nature, Lond. 230, 155-157.

Merra Khan P. M., Westerveld A., Grzeschik K. H., Deys B. F., Garson O. M. \& Siniscalco M. (1971). X linkage of human phosphoglycerate kinase confirmed in man-mouse and man-chinese hamster somatic cell hybrids. Am. J. Hum. Genet. 23. 614-622.

Oelshlegel F. J., Jr. \& Brewer G. J. (1972) New positive, tetrazolim linked, staining method for use with electrophoresis of phosphoglycerate kinase. Experientia 28, 116$117,1264$.

RitTER H. \& SCHMitT J. (1974) Interspecific variability of red cell phosphoglycerate kinase in primates. Humangenetik 21, 93-96.

Valentine W. N., Hsieh H., Paglia D. E., Anderson H. M., Baughan M. A., Jaffé E. R. \& Garson O. M. (1969) Hereditary hemolytic anemia associated with phosphoglycerate kinase deficiency in erythrocytes and leukocytes. New Engl. J. Med. 280, 528-534.

VandeBerg J. L., Cooper D. W. \& Sharman G. B. (1973). Phosphoglycerate kinase polymorphism in the wallaby Macropus parryi: activity of both $\mathrm{X}$ chromosomes in the muscle. Nature New Biol. 243, 47-48.

Key Word Index-Drosophila; phosphoglycerate kinase. 